\title{
Abnormal $\alpha$ to $\gamma$ Transformation Behavior of Steels with a Martensite and Bainite Microstructure at a Slow Reheating Rate
}

\author{
Takuya HARA, ${ }^{1)}$ Naoki MARUYAMA, ${ }^{1)}$ Yasuhiro SHINOHARA, ${ }^{2)}$ Hitoshi ASAHI, ${ }^{2)}$ Genichi SHIGESATO, \\ Masaaki SUGIYAMA ${ }^{3)}$ and Toshihiko KOSEKI') \\ 1) Kimitsu R\&D Lab., Nippon Steel Corporation, 1 Kimitsu, Kimitsu, Chiba 299-1141 Japan. \\ 2) Steel Research Laboratories, Nippon Steel Corporation, 20-1 Shintomi, Futtsu, Chiba 293-8511 Japan. \\ 3) Advanced Technology Research Laboratories, Nippon Steel Corporation, 20-1 Shintomi, Futtsu, Chiba $293-8511$ Japan. \\ 4) Department of Materials Engineering, The University of Tokyo, 7-3-1 Hongo, Bunkyo-ku, Tokyo 113-8656 Japan.
}

(Received on May 13, 2009; accepted on July 24, 2009)

\begin{abstract}
The same coarse austenite $(\gamma)$ grains as those before austenitizing emerge when a martensite or bainite steel with coarse grains is reheated to an austenite region at a slow reheating rate. This is called abnormal ferrite $(\alpha)$ to austenite $(\gamma)$ transformation or $\gamma$ grain memory. In this paper, $\alpha$ to $\gamma$ transformation behavior is investigated in order to clarify the mechanism of abnormal $\alpha$ to $\gamma$ transformation from the viewpoint of the roles of cementite and retained $\gamma$. (1) Coarse $\gamma$ grains and fine globular $\gamma$ grains that nucleate along the coarse $\gamma$ grain boundaries are formed when bainite or martensite steel is reheated above the $\mathrm{A}_{\mathrm{C} 3}$ temperature. The size distribution of $\gamma$ grain is the same as that before reheating. (2) Coarse $\gamma$ grains are formed by the growth, impingement, and coalescence of acicular $\gamma$ grains that corresponds to retained $\gamma$ between laths. (3) Abnormal $\alpha$ to $\gamma$ transformation is suppressed by decreasing the amount of retained $\gamma$ and by increasing the amount of cementite before reheating. These results suggest that $\alpha$ to $\gamma$ transformation behavior is governed by competition between the nucleation and growth of newly formed $\gamma$ from the dissolution of cementite and the growth and coalescence of retained $\gamma$. Abnormal $\alpha$ to $\gamma$ transformation occurs when the growth and coalescence of retained $\gamma$ dominates rather than the nucleation and growth of globular $\gamma$ grains.
\end{abstract}

KEY WORDS: transformation; memory effect; cementite; retained austenite; nucleation; coalescence.

\section{Introduction}

There are some cases where the same austenite $(\gamma)$ grains as those before austenitizing emerge when a martensite or bainite microstructure in prior austenite grains is reheated to an austenite region. This is called abnormal $\alpha$ to $\gamma$ transformation or $\gamma$ grain memory. Figure 1 shows the schematic diagram of abnormal $\alpha$ to $\gamma$ transformation or $\gamma$ grain memory. This phenomenon appears under slow or rapid heating rate. Austenite grains are refined and become uniform with an increase in the austenitizing temperature after the same $\gamma$ grains as those before reheating appear. Researches on abnormal $\alpha$ to $\gamma$ transformation were intensively conducted from the 1950 to the 1980 s. $^{1-11)}$ Previous reports are summarized below.

(1) Nehrenberg ${ }^{1)}$ investigated the effect of the reheating rate on $\alpha$ to $\gamma$ transformation behavior and reported that in bainite or martensite steels, acicular $\gamma$ grains nucleate on the packet or lath boundaries.

(2) Sadovskii ${ }^{2)}$ reported that it is possible to reconstitute the original prior $\gamma$ grains by the coalescence of acicular $\gamma$ grains. He also reported that this reconstitution is observed at rapid and slow reheating rates, but not at intermediate reheating rates.

(3) Sadovskii and Sokolov ${ }^{3)}$ identified that the overall process of $\gamma$ formation in the grain interiors has two stages. The first stage is the transformation to acicular $\gamma$ grain and the second stage is austenite recrystallization. They also reported that lowering the reheating rate and increasing the alloy content promote $\gamma$ grain memory.

(4) A group of Webster and Allen ${ }^{4)}$ and a group of Kula and Cohen ${ }^{5)}$ stated that the effect of the reheating rate on $\gamma$ grain memory is dependent on the carbide distribution before and during $\alpha$ to $\gamma$ transformation.

(5) D'Yachenko and Federov ${ }^{6}$ ) showed that acicular $\gamma$ grains and martensite have the Kurdjmov-Sachs orientation relationship and that acicular $\gamma$ grains are formed by a diffusionless shear mechanism.

(6) Matsuda and Okamura ${ }^{7,8)}$ found that both acicular $\gamma$ and globular $\gamma$ grains are formed in the early stages of $\gamma$ formation. Globular $\gamma$ grains are the result of normal diffusion-controlled growth accompanying the dissolution of cementite. This is called normal diffusion reverse transformation. However, acicular $\gamma$ grains are believed to be formed by reverse martensite transformation. The coalescence of acicular $\gamma$ grains with the same orientation results in a reconstitution of the original prior $\gamma$ grains. When recrystallization of acicular $\gamma$ grains in the $\gamma$ region does not occur, coarse $\gamma$ grains are refined. Globular $\gamma$ grains increase with an increasing reheating rate. At a slow reheating rate, ce- 


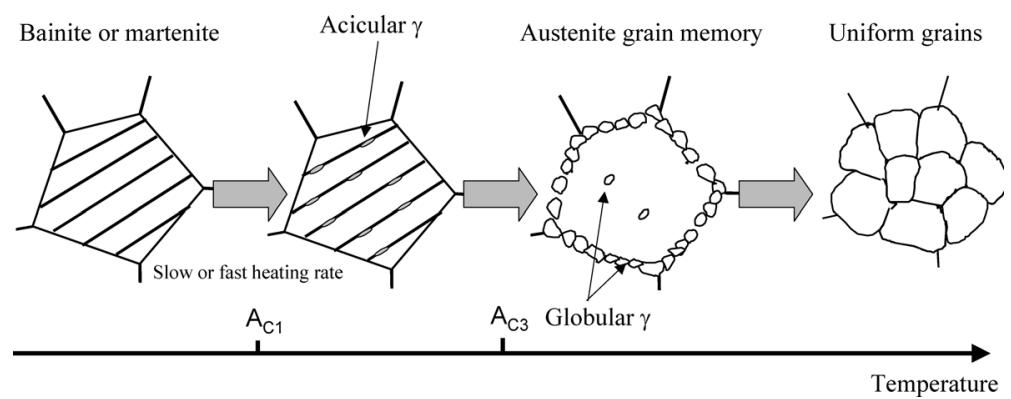

Fig. 1. Schematic drawing of abnormal $\alpha$ to $\gamma$ transformation.

mentite is stabilized by the concentration of alloying elements such as manganese or nickel in cementite and does not dissolve easily before $\alpha$ to $\gamma$ transformation. Therefore, the addition of the alloying elements promotes $\gamma$ grain memory. The addition of boron also promotes $\gamma$ grain memory.

(7) Watanabe and Kunitake ${ }^{9)}$ reported that the orientation relationship between cementite and $\alpha$ is the Bagaryatskii relationship, the relationship between $\alpha$ and $\gamma$ is the Kurdjmov-Sachs relationship and the relationship between $\gamma$ and cementite is the Pitch relationship. Therefore, one orientation of $\gamma$ to satisfy these relationships is determined. Acicular $\gamma$ grains with the same orientation were formed and coarse $\gamma$ grains are formed by the coalescence of such acicular $\gamma$ grains.

(8) Homma ${ }^{10)}$ concluded that all alloying elements, especially nickel, favor the reconstruction of the original prior $\gamma$ grains. He suggests that this is because the presence of these elements increased the intensity of acicular $\gamma$ nucleation.

(9) Plichata and Aaronson ${ }^{11)}$ reported that the nucleation and growth of $\gamma$ occurred at lath martensite boundaries and $\gamma$ grew due to the diffusion control rather than due to the shear mechanism.

(10) Kimmins and Gpooch ${ }^{12)}$ stated that globular $\gamma$ and acicular $\gamma$ grains are observed in austenite. Globular $\gamma$ grains were formed by the dissolution of cementite, and acicular $\gamma$ grains were formed by the growth of retained $\gamma$. Acicular $\gamma$ grains within a given prior $\gamma$ grain have the same orientation because of the growth of the retained $\gamma$. They coalesce on impingement. This leads to a reconstitution of the original prior $\gamma$ grains.

As mentioned above, three mechanisms concerning the appearance of abnormal $\alpha$ to $\gamma$ transformation have been proposed: (i) martensite reverse transformation, (ii) the restriction of crystal orientation attributed to the orientation relationship among cementite, ferrite and austenite, and (iii) the coalescence of retained $\gamma$. A consistent interpretation has not been established yet. Moreover, there is no consensus on whether the mechanism of abnormal $\alpha$ to $\gamma$ transformation is the shear process or the diffusion controlled process. Furthermore, it has not been clarified whether the three mechanisms are correct and whether another mechanism of abnormal $\alpha$ to $\gamma$ transformation exists.

Therefore, in this study, $\alpha$ to $\gamma$ transformation in steels with a bainite and/or martensite microstructure was investigated at a slow reheating rate in order to clarify the mechanism of abnormal $\alpha$ to $\gamma$ transformation. The reason that $\alpha$ to $\gamma$ transformation behavior was investigated at a slow re-
Table 1. Chemical compositions of tested steels (mass\%, *: ppm).

\begin{tabular}{|c|c|c|c|c|c|c|c|c|c|}
\hline & $\mathrm{C}$ & $\mathrm{Si}$ & $\mathrm{Mn}$ & $\mathrm{Ni}$ & $\mathrm{Cr}$ & $\mathrm{Mo}$ & $\mathrm{Ti}$ & $\mathrm{Al}$ & $\mathrm{B}^{*}$ \\
\hline NB & 0.05 & 0.10 & 1.90 & 0.49 & 0.29 & 0.30 & 0.015 & 0.015 & 9 \\
\hline NM & 0.07 & 0.25 & 1.86 & 0.36 & 0.60 & 0.46 & 0.015 & 0.003 & - \\
\hline
\end{tabular}

Table 2. Chemical compositions of tested steels (mass $\%$, *: ppm).

\begin{tabular}{|c|c|c|c|c|c|c|c|c|}
\hline & $\mathrm{C}$ & $\mathrm{Si}$ & $\mathrm{Mn}$ & $\mathrm{Ni}$ & $\mathrm{Mo}$ & $\mathrm{Ti}$ & $\mathrm{Al}$ & $\mathrm{B}^{*}$ \\
\hline BA1 & 0.005 & 0.20 & 1.50 & 2.98 & - & 0.011 & 0.028 & 9 \\
\hline BA2 & 0.05 & 0.20 & 1.50 & 3.01 & - & 0.011 & 0.028 & 9 \\
\hline BA3 & 0.45 & 0.20 & 1.50 & 3.01 & - & 0.011 & 0.028 & 5 \\
\hline BD & 0.30 & 0.30 & 1.50 & - & - & - & 0.020 & - \\
\hline BE & 0.30 & 1.00 & 1.50 & - & - & - & 0.022 & - \\
\hline FAT1 & 0.05 & 0.10 & 0.50 & 4.65 & 0.50 & 0.015 & 0.015 & 10 \\
\hline FAT2 & 0.05 & 0.10 & 2.00 & 0.90 & 0.50 & 0.015 & 0.015 & 10 \\
\hline FAT3 & 0.11 & 0.10 & 0.50 & 3.75 & 0.50 & 0.015 & 0.015 & 10 \\
\hline FAT4 & 0.11 & 0.10 & 2.00 & 0.00 & 0.50 & 0.015 & 0.015 & 10 \\
\hline
\end{tabular}

heating rate was because abnormal $\alpha$ to $\gamma$ transformation was frequently observed for low-carbon high-alloy steels in slab reheating of plate rolling.

\section{Experimental Procedure}

\subsection{Materials}

The chemical compositions of the tested steels are shown in Tables 1 and 2. Steel NM, which is low-carbon, highmanganese, nickel, molybdenum, boron-free steel and steel NB with a similar chemical composition to steel NM except for the addition of boron were melted in a 300-ton LD converter and continuous cast. These are high strength linepipe steels, and the $\alpha$ to $\gamma$ transformation behavior for these steels was investigated because abnormal $\alpha$ to $\gamma$ transformation occurred for these steels in slab reheating of plate rolling.

$\mathrm{BA}, \mathrm{BD}$, and $\mathrm{BE}$ steels with different carbon contents ranging from 0.005 to $0.45 \%$, and FAT steels with different manganese and nickel contents were melted in a $50-\mathrm{kg}$ VIM (vacuum induction melting) in a laboratory and cast into $50-\mathrm{kg}$ ingots.

$\mathrm{NM}, \mathrm{NB}$, and FAT steels were used for as-continuouscast slabs or ingots because these steels have a bainite microstructure for as-continuous-cast slabs or ingots. On the other hand, BA, BD, and $\mathrm{BE}$ steels that were quenched after reheating at $1350^{\circ} \mathrm{C}(1623 \mathrm{~K})$ for $1 \mathrm{~h}$ in order to obtain a bainite or martensite microstructure were used for the test.

A specimen of $10 \mathrm{~mm}$ in width, $10 \mathrm{~mm}$ in thickness, and $20 \mathrm{~mm}$ in length was machined from the quarter-thickness of a continuous-cast slab or an ingot. $\alpha$ to $\gamma$ transformation behavior was investigated using these block specimens. 

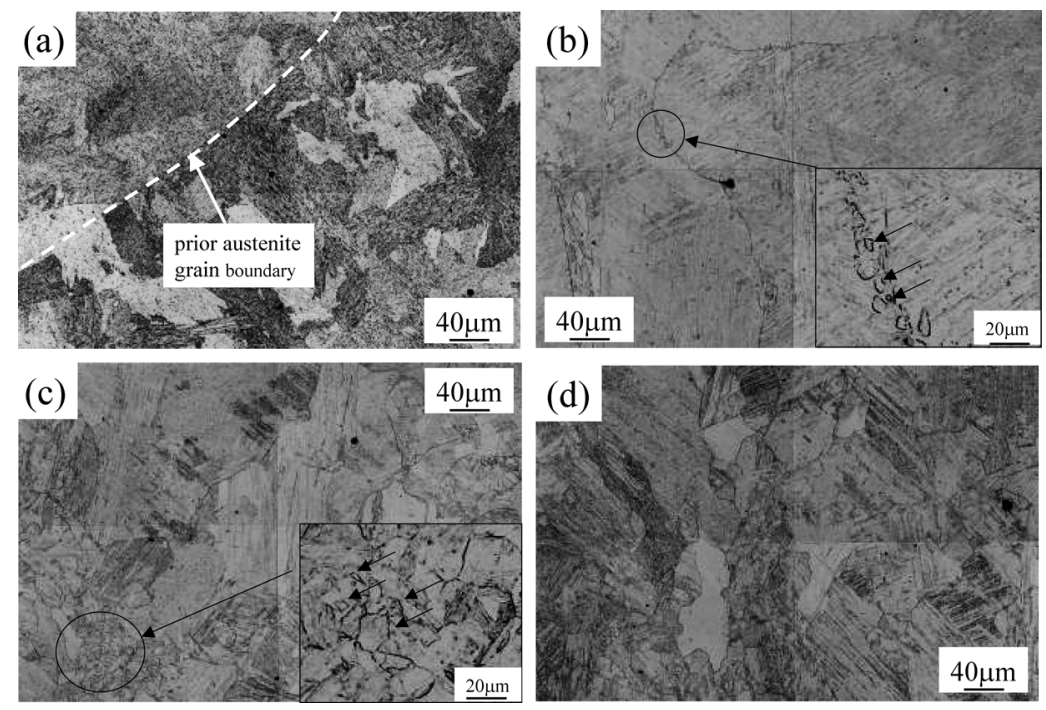

Fig. 2. Austenite grain distribution quenched after being austenitized in various temperature. (NB steel). Reheating temperature: (a) before reheating, (b) $1000^{\circ} \mathrm{C}$, (c) $1100^{\circ} \mathrm{C}$, (d) $1200^{\circ} \mathrm{C}$.

The block specimens heated with a constant slow heating rate of $0.13^{\circ} \mathrm{C} / \mathrm{s}$ were quenched immediately after reaching the reheating temperature range from $650^{\circ} \mathrm{C}(923 \mathrm{~K})$ to $1200^{\circ} \mathrm{C}(1473 \mathrm{~K})$. The heating rate of $0.13^{\circ} \mathrm{C} / \mathrm{s}$ is similar to the slab-reheating rate in the plate rolling process. In order to investigate the effect of the volume fraction of retained $\gamma$ and cementite on $\alpha$ to $\gamma$ transformation behavior, some specimens were subzero-treated, where the specimens were immersed in liquid nitrogen and/or tempered at $550^{\circ} \mathrm{C}$ for $1 \mathrm{~h}$, then reheated to various temperatures ranging from 850 to $950^{\circ} \mathrm{C} . \mathrm{A}_{\mathrm{C} 3}$ temperature of NB and NM steels was measured from the thermal dilatation.

\subsection{Microstructure Observation}

The microstructure was observed using an optical microscope (OM), a scanning electron microscope (SEM), and an electron back scattering diffractometer (EBSD). For optical microscopy and scanning electron microscopy, nital solution composed of $3 \%$ nitric acid and $97 \%$ ethanol and a solution that was composed of sodium dodecyl benzenesulfonic acid and picric acid were used as the etching solutions.

\subsection{X-ray Diffraction Measurement}

The volume fraction of retained $\gamma$ was measured by Xray diffractometry from the ratio of the diffraction intensity of (200), (220), and (311) in an fcc structure and that of (200) and (220) in a bcc structure. The average volume fraction of retained $\gamma$ is adopted.

\section{Results}

\subsection{Effect of Reheating Temperature on the Distribu- tion of $\gamma$ Grains}

The effect of the reheating temperature on the distribution of $\gamma$ grains was investigated for steel reheated to a temperature of $650^{\circ} \mathrm{C}(923 \mathrm{~K})$ to $1200^{\circ} \mathrm{C}(1473 \mathrm{~K})$ at a slow reheating rate of $0.13^{\circ} \mathrm{C} / \mathrm{s}$ for $\mathrm{NB}$ and $\mathrm{NM}$ steels. $\mathrm{A}_{\mathrm{C} 3}$ temperature of $\mathrm{NB}$ and $\mathrm{NM}$ steels was $900^{\circ} \mathrm{C}$ from the thermal dilatation measurement. The distribution of $\gamma$ grains of the

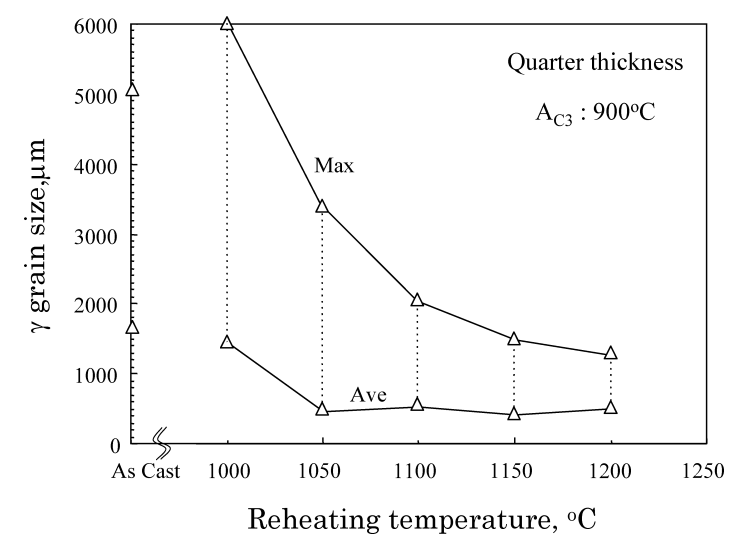

Fig. 3. Effect of reheating temperature on $\gamma$ grain size (NB steel).

specimens quenched after reheating at $1000^{\circ} \mathrm{C}, 1100^{\circ} \mathrm{C}$, and $1200^{\circ} \mathrm{C}$ for $1 \mathrm{~h}$ are shown in Fig. 2. Prior $\gamma$ grain before reheating is also indicated in Fig. 2(a). Coarse prior $\gamma$ grains with a size exceeding $1 \mathrm{~mm}$ in diameter in the specimen reheated at $1000^{\circ} \mathrm{C}$ were observed as seen in Fig. 2(b). Coarse grains similar to those before reheating were formed. Fine globular grains with a grain size of $5 \mu \mathrm{m}$ that formed along the coarse prior $\gamma$ grain boundaries are seen in the magnification of Fig. 2(b). The coarse $\gamma$ grain of specimens reheated at $1100^{\circ} \mathrm{C}$ as shown in Fig. 2(c) was suppressed in contrast with that reheated at $1000^{\circ} \mathrm{C}$ as indicated in Fig. 2(b). Simultaneously, many globular grains with a grain size of $10 \mu \mathrm{m}$ were formed as indicated by the arrows of Fig. 2(c). The fine globular grains grew due to the increase in the reheating temperature. Coarse $\gamma$ grain size remarkably decreased in the specimen reheated at $1200^{\circ} \mathrm{C}$ as indicated in Fig. 2(d), and more uniform grains were formed compared to those in the specimen reheated at $1000^{\circ} \mathrm{C}$ or $1100^{\circ} \mathrm{C}$. The $\alpha$ to $\gamma$ transformation behavior of $\mathrm{NM}$ steel reheated from 1000 to $1200^{\circ} \mathrm{C}$ at a slow reheating rate was the same as that for NB steel as mentioned above.

Figure 3 shows the effect of the reheating temperature on $\gamma$ grain size. The maximum and average $\gamma$ grain sizes 
were $6 \mathrm{~mm}$ and $1.5 \mathrm{~mm}$, respectively, in the specimen reheated at $1000^{\circ} \mathrm{C}$, and were the same as those before reheating. The maximum and average $\gamma$ grain size became smaller with an increase in the reheating temperature. The maximum and average $\gamma$ grain size also decreased with an increase in the reheating temperature for NM steel.

These results show that coarse $\gamma$ grains were formed when reheating just above the $\mathrm{A}_{\mathrm{C} 3}$ temperature and the $\gamma$ grain size was reduced with an increase in the reheating temperature. These phenomena were identified with abnormal $\alpha$ to $\gamma$ transformation, in other words, $\gamma$ grain memory. The reason why $\gamma$ grain size was reduced with an increase in the reheating temperature is thought to be that the grain growth of fine globular $\gamma$ nucleated from prior $\gamma$ boundaries occurs to reduce the interfacial energy in the coarse $\gamma$ grains which was caused by the growth and coalescence of retained $\gamma$. This subject will be investigated in future work.

\subsection{Microstructure Observation of the Specimens Heated at Slow Reheating Rates}

An abnormal $\alpha$ to $\gamma$ transformation appeared in NB and $\mathrm{NM}$ steels reheated at $0.13^{\circ} \mathrm{C} / \mathrm{s}$ as mentioned in 3.1. Microstructure observation was carried out for NB and NM steels quenched from the temperatures of 750, 850 and $950^{\circ} \mathrm{C}$.
The distribution of retained $\gamma$ before reheating was investigated using the EBSP method. Figure 4 indicates the distribution of retained $\gamma$ in NB cast steel. Large amounts of retained $\gamma$ at the interlath with the same crystal orientation were formed as indicated by the arrows in Fig. 4(b). In NB cast steel, $2 \%$ volume fraction of retained $\gamma$ was measured before reheating using the X-ray diffraction pattern and image analysis from EBSP. In NM cast steel, 6 to $7 \%$ volume fraction of retained $\gamma$ was also measured.

Scanning electron micrographs of NB cast steel quenched after reheating at temperatures from 750, 800 and $850^{\circ} \mathrm{C}$, which are in the $(\alpha+\gamma)$ dual-phase region are shown in Figs. 5(a), 5(b) and 5(c). Fine needle-shaped MAs, a few $\mu \mathrm{m}$ in length and white in appearance, which are indicated by the arrows in Fig. 5(a), were observed along the lath boundary. At a reheating temperature of $800^{\circ} \mathrm{C}$, fine acicular $\gamma$ grains, a few $\mu \mathrm{m}$ in size, grew in a manner similar to that of rod-shaped $\gamma$. Acicular $\gamma$ grains partially coalesced as indicated by the arrows in the high magnification of Fig. 5(b). Moreover, many acicular $\gamma$ grains grew, collided, and coalesced at a reheating temperature of $850^{\circ} \mathrm{C}$ as indicated in Fig. 5(c). (The hollow area is untransformed regions.) An optical micrograph of NB cast steel quenched after reheating at $950^{\circ} \mathrm{C}$, which is in the $\gamma$ region is indicated in Fig. 5(d). Coarse $\gamma$ grains were formed at $950^{\circ} \mathrm{C}$
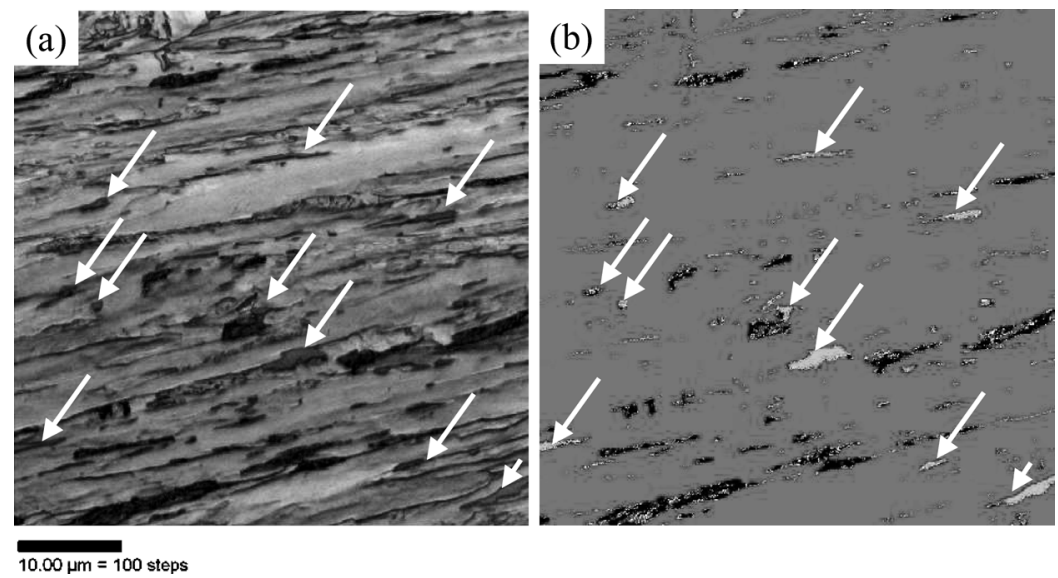

Fig. 4. EBSP analysis of NB cast steel. (a) Image quality map, (b) ferrite and austenite mapping.
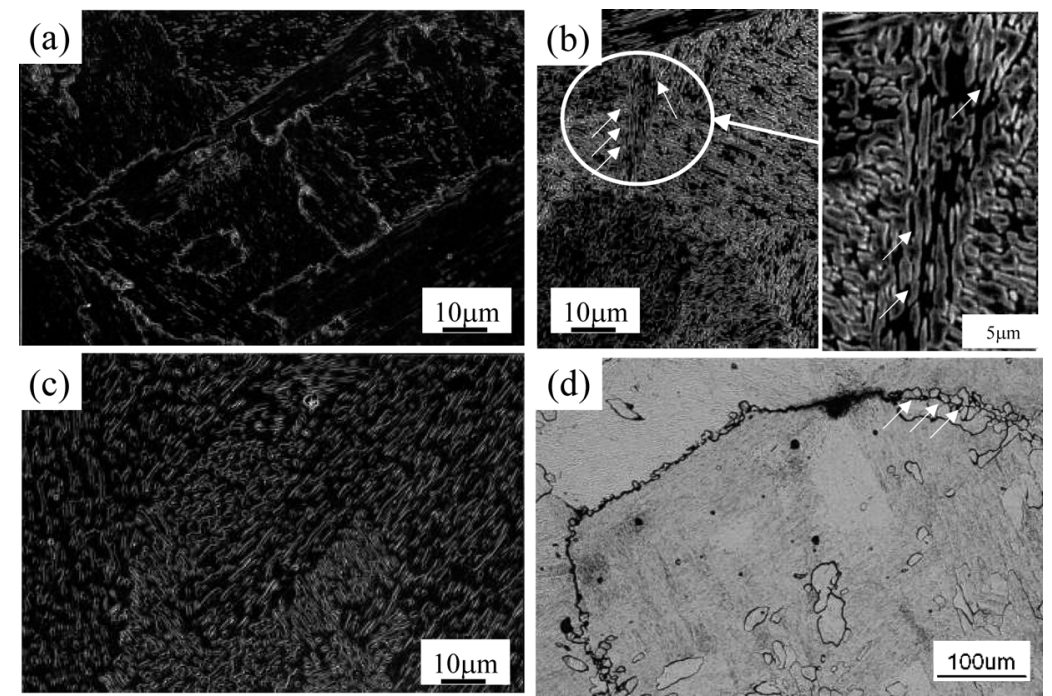

Fig. 5. SEM images and optical micrograph of NB steel quenched after being reheated at various temperature. Reheating temperature: (a) $750^{\circ} \mathrm{C}$, (b) $800^{\circ} \mathrm{C}$, (c) $850^{\circ} \mathrm{C}$, (d) $950^{\circ} \mathrm{C}$. 
just above the $\mathrm{A}_{\mathrm{C} 3}$ temperature as shown in Fig. 5(d). Many fine globular $\gamma$ grains were formed along the coarse $\gamma$ grain boundaries as indicated by the arrows in Fig. 5(d). The coarse $\gamma$ grain size distribution when austenitizing at $950^{\circ} \mathrm{C}$ was the same level as that at $1000^{\circ} \mathrm{C}$ as indicated in Fig. 2(b). The $\alpha$ to $\gamma$ transformation behavior in the $(\alpha+\gamma)$ dual-phase region for NM steel was the same as that for NB steel.

\subsection{Effect of Tempering and Subzero Treatment on $\alpha$ to $\gamma$ Transformation Behavior}

The effect of tempering treatment and subzero treatment on abnormal $\alpha$ to $\gamma$ transformation in NB and NM cast steels was investigated. Generally, normal $\alpha$ to $\gamma$ transformation occurred when many globular $\gamma$ grains were formed in a coarse prior $\gamma$ grain. Abnormal $\alpha$ to $\gamma$ transformation occurred when few globular $\gamma$ grains were formed in the coarse prior $\gamma$ grain. Therefore, whether abnormal $\alpha$ to $\gamma$ transformation had occurred or not due to tempering and/or subzero treatment was investigated by means of microstructure observation.

Figure 6 shows an SEM image of NB steel after tempering at $550^{\circ} \mathrm{C}$ for $1 \mathrm{~h}$ and optical micrographs of NB steel quenched from 850 and $950^{\circ} \mathrm{C}$ at the slow reheating rate of $0.13^{\circ} \mathrm{C} / \mathrm{s}$. Much cementite as well as M-As were formed along the lath boundary of NB steel after tempering as indicated by the arrows in Fig. 6(a). In the case of NB tempered steel quenched after reheating at $850^{\circ} \mathrm{C}$, many globular $\gamma$ grains were formed in the coarse grains, as indicated by the black arrows and the magnified portion in Fig. 6(b), in ad- dition to globular $\gamma$ grains that nucleated along the coarse grain boundary, as shown by the white arrows in Fig. 6(b). Abnormal $\alpha$ to $\gamma$ transformation was suppressed due to the tempering treatment. Coarse $\gamma$ grains still partially remained in the NB tempered steel quenched after reheating $950^{\circ} \mathrm{C}$ as indicated by the white arrows in Fig. 6(c).

The effect of combined subzero treatment and tempering on abnormal $\alpha$ to $\gamma$ transformation in NB steel was investigated. In the subzero treatment, the specimens were immersed in liquid nitrogen for $1 \mathrm{~h}$. Figure 7 shows SEM images of the steel tempered at $550^{\circ} \mathrm{C}$ for $1 \mathrm{~h}$ after subzero treatment and optical micrographs of the subzero-treated and tempered steel quenched after reheating at 850 and $950^{\circ} \mathrm{C}$. Much cementite was formed along the lath boundary in the bainite microstructure in NB steel after subzero and tempering treatment as indicated in Fig. 7(a). The volume fraction of cementite in the steel after subzero and tempering treatment is larger than that after tempering. Many globular $\gamma$ grains were formed in the coarse grains indicated by the black arrows in Fig. 7(b) as well as along the grain boundaries of coarse grains shown by the white arrows in Fig. 7(b). Abnormal $\alpha$ to $\gamma$ transformation was remarkably suppressed in NB steel after subzero and tempering treatment in contrast with that in NB steel after only tempering. Abnormal $\alpha$ to $\gamma$ transformation was suppressed in only subzero treated NB steel.

An SEM image of NM steel, which was tempered at $550^{\circ} \mathrm{C}$ after subzero treatment is shown in Fig. 8(a). Many M-As were formed along the lath boundaries in the coarse bainite microstructure in NM steel as seen by the arrows in
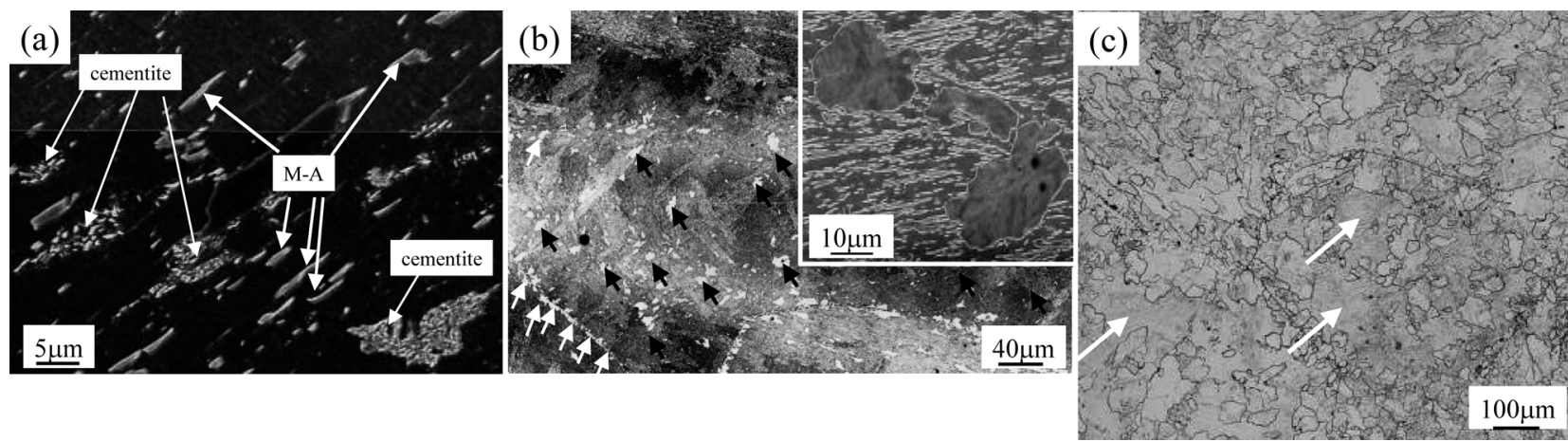

Fig. 6. $\alpha$ to $\gamma$ transformation behavior in tempered NB steel. (a) SEM image of NB steel tempered at $550^{\circ} \mathrm{C}$. (b) Optical micrograph of NB steel tempered at $550^{\circ} \mathrm{C}$, then reheated at $850^{\circ} \mathrm{C}$. (c) Optical micrograph of NB steel tempered at $550^{\circ} \mathrm{C}$, then reheated at $950^{\circ} \mathrm{C}$.
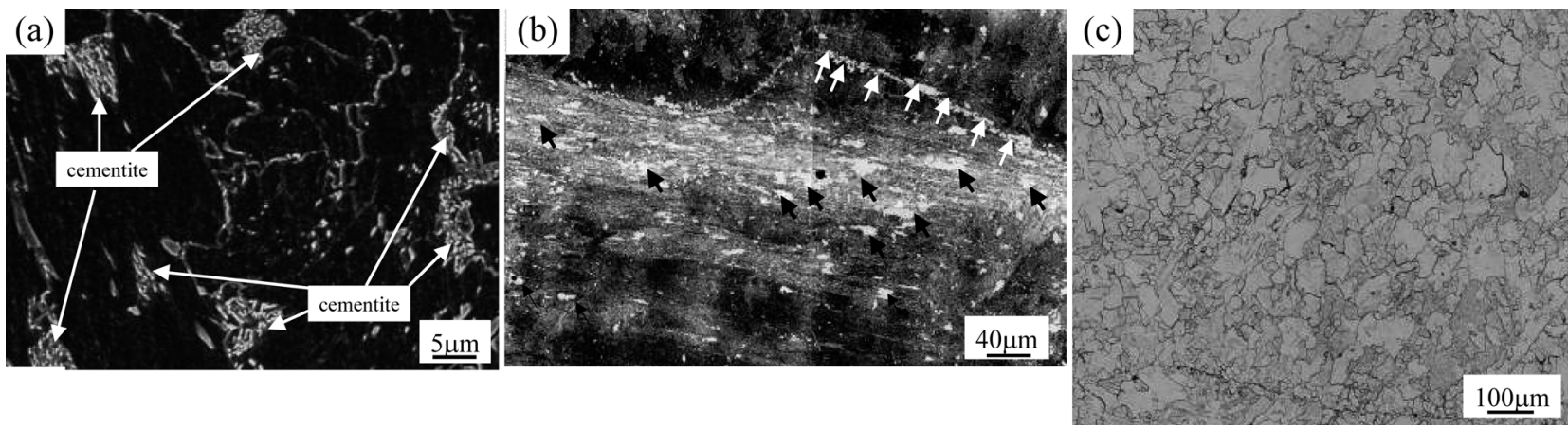

Fig. 7. $\alpha$ to $\gamma$ transformation behavior in sub-zero treated and tempered NB steel. (a) SEM image of NB steel sub-zero treated and tempered at $550^{\circ} \mathrm{C}$. (b) Optical micrograph of NB steel sub-zero treated and tempered, then reheated at $850^{\circ} \mathrm{C}$. (c) Optical micrograph of NB steel sub-zero treated and tempered, then reheated at $950^{\circ} \mathrm{C}$. 

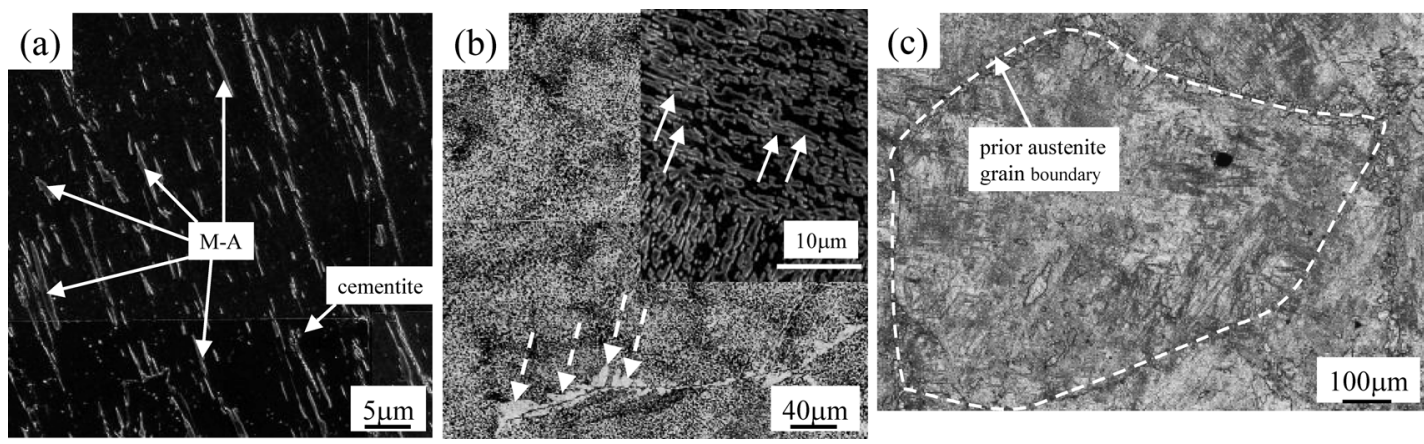

Fig. 8. $\alpha$ to $\gamma$ transformation behavior in sub-zero treated and tempered NM steel. (a) SEM image of NM steel sub-zero treated and tempered at $550^{\circ} \mathrm{C}$. (b) Optical micrograph of NM steel sub-zero treated and tempered at $550^{\circ} \mathrm{C}$, then reheated at $850^{\circ} \mathrm{C}$. (c) Optical micrograph of NM steel sub-zero treated and tempered at $550^{\circ} \mathrm{C}$, then reheated at $950^{\circ} \mathrm{C}$.

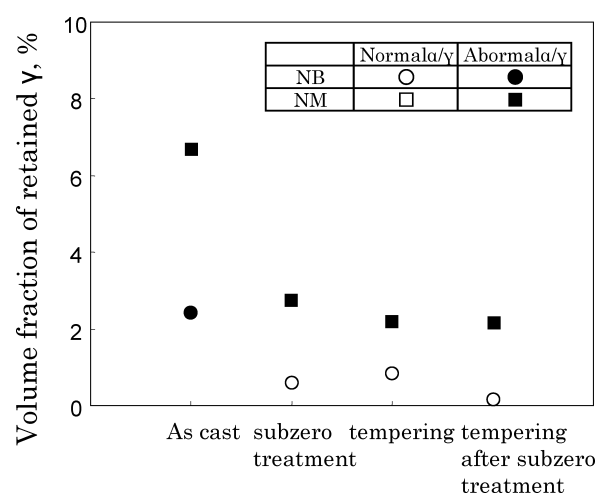

Fig. 9. Effect of tempering and subzero treatment on retained $\gamma$ fraction (NB and NM steels). Subzero treatment: Specimens are immersed in liquid nitrogen for $1 \mathrm{~h}$. Tempering: Specimens are heated at $550^{\circ} \mathrm{C}$ for $1 \mathrm{~h}$

Fig. 8(a). A small amount of cementite was formed along the lath boundaries in the coarse bainite microstructure. An SEM image and optical micrograph of this tempered and subzero treated NM steel after reheating at $850^{\circ} \mathrm{C}$ are shown in Fig. 8(b). Many acicular $\gamma$ grains were formed along the lath boundary when quenched after reheating at $850^{\circ} \mathrm{C}$ as indicated by the white arrows in Fig. 8(b). Many globular $\gamma$ grains observed as white globules and indicated by the white dotted arrows in Fig. 8(b) were formed along the coarse grain boundary. Abnormal $\alpha$ to $\gamma$ transformation occurred at a reheating temperature of $950^{\circ} \mathrm{C}$ for NM steel regardless of whether tempering treatment was carried out after subzero treatment as shown in Fig. 8(c).

Figure 9 shows the effects of subzero treatment and tempering at $550^{\circ} \mathrm{C}$ for $1 \mathrm{~h}$ on the volume fraction of retained $\gamma$ in NB and NM steels. In subzero treatment, the specimens were immersed in liquid nitrogen. The volume fraction of retained $\gamma$ was reduced to less than $1 \%$ due to subzero or tempering treatment or combined subzero and tempering treatment although the volume fraction of retained $\gamma$ was more than $2 \%$ for NB cast steel. In particular, the volume fraction of retained $\gamma$ was less than $0.1 \%$ in NB steel after combined subzero treatment and tempering. Most of the retained $\gamma$ was decomposed into cementite and ferrite due to the combined treatment. Abnormal $\alpha$ to $\gamma$ transformation was remarkably suppressed by applying tempering treatment and/or subzero treatment. On the other hand, the volume fraction of retained $\gamma$ of more than $2 \%$ still remained
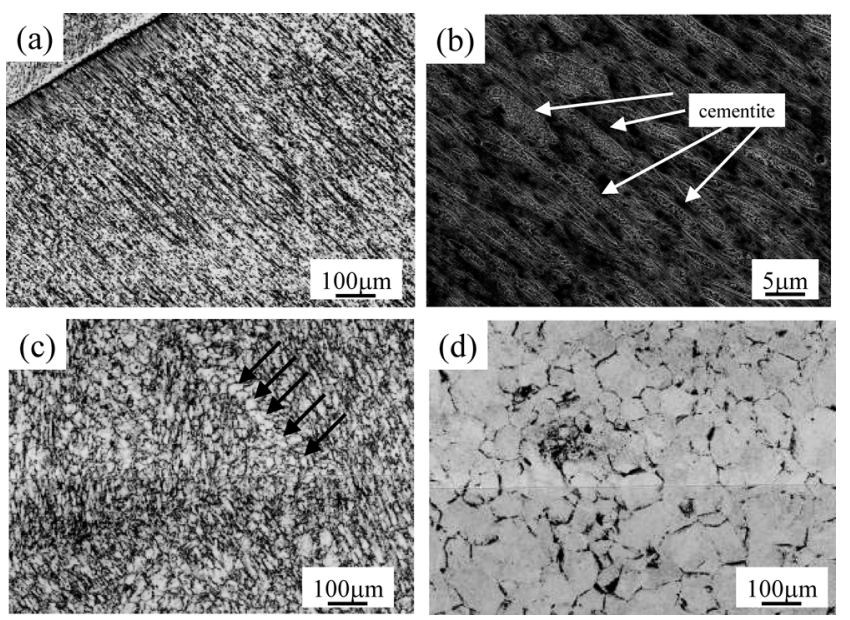

Fig. 10. $\alpha$ to $\gamma$ transformation behavior in BE steel. (a) Optical micrograph of $\mathrm{BE}$ steel reheated at $1350^{\circ} \mathrm{C}$. (b) SEM image of $\mathrm{BE}$ steel reheated at $1350^{\circ} \mathrm{C}$. (c) Optical micrograph of $\mathrm{BE}$ steel reheated at $1350^{\circ} \mathrm{C}$ followed by quenching, then reheated at $850^{\circ} \mathrm{C}$. (d) Optical micrograph of $\mathrm{BE}$ steel reheated at $1350^{\circ} \mathrm{C}$ followed by quenching, then reheated at $1050^{\circ} \mathrm{C}$.

although the volume fraction of retained $\gamma$ was reduced from 7 to $2 \%$ due to subzero or tempering treatment or combined subzero and tempering treatment for NM steel. Therefore, abnormal $\alpha$ to $\gamma$ transformation occurred irrespective of the tempering treatment and/or subzero treatment for NM steel.

These results indicate that when the volume fraction of retained $\gamma$ was reduced to $1 \%$ or lower due to subzero treatment and/or tempering treatment, abnormal $\alpha$ to $\gamma$ transformation was remarkably suppressed. However, when the volume fraction of retained $\gamma$ still remained above $2 \%$ due to subzero treatment and/or tempering treatment, abnormal $\alpha$ to $\gamma$ transformation still appeared.

\section{4. $\alpha$ to $\gamma$ Transformation in Low Alloy Steels with a Carbon Content of $0.1 \%$ or Higher}

$\alpha$ to $\gamma$ transformation in low alloy steels with a carbon content of $0.1 \%$ or higher was investigated. Figure 10 shows $\alpha$ to $\gamma$ transformation behavior in BE steel with a carbon content of $0.3 \%$. A bainite structure was obtained in $\mathrm{BE}$ steel quenched from $1350^{\circ} \mathrm{C}$ as indicated in Fig. 10(a). Much fine cementite was formed within lath as indicated by the arrows in Fig. 10(b). Many globular $\gamma$ grains observed 


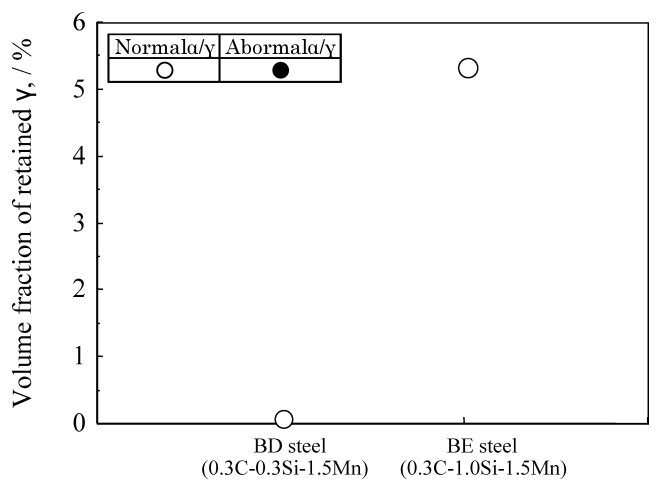

Fig. 11. Relationship between $\alpha / \gamma$ transformation behavior and volume fraction of retained $\gamma$ for $0.3 \%$ carbon steels with different silicon content. (Volume fraction of retained $\gamma$ was measured using X-ray diffractometry for $\mathrm{BD}$ and $\mathrm{BE}$ steels quenched after being reheated at $1350^{\circ} \mathrm{C}$.)

as being white as seen by the arrows in Fig. 10(c) were formed in coarse grains in the specimen reheated at $850^{\circ} \mathrm{C}$. Moreover, $100-\mu \mathrm{m}$ uniform $\gamma$ grains were observed at a reheating temperature of $1050^{\circ} \mathrm{C}$. That is, abnormal $\alpha$ to $\gamma$ transformation did not occur in BE steel with a carbon content of $0.3 \%$. Abnormal $\alpha$ to $\gamma$ transformation did not occur in BD steel the chemical composition of which was $0.3 \% \mathrm{C}-0.3 \% \mathrm{Si}$. Figure 11 shows the relationship between $\alpha$ to $\gamma$ transformation behavior and the volume fraction of retained $\gamma$ in $\mathrm{BD}$ and $\mathrm{BE}$ steels quenched from $1350^{\circ} \mathrm{C}$. No abnormal $\alpha$ to $\gamma$ transformation was observed because the volume fraction of retained $\gamma$ for BD steel was less than $0.1 \%$. Moreover, in case of BE steel, abnormal $\alpha$ to $\gamma$ transformation was also suppressed with a carbon content of $0.3 \%$ irrespective of the high volume fraction of retained $\gamma$ of more than $5 \%$.

\subsection{Effect of Retained $\gamma$ and Carbon Content on $\alpha$ to $\gamma$ Transformation Behavior}

The volume fractions of retained $\gamma$ for bainite and martensite steels indicated in Tables 1 and 2 were measured by means of X-ray analysis. The microstructure quenched from the temperature of $950^{\circ} \mathrm{C}$ or $1000^{\circ} \mathrm{C}$ above $\mathrm{A}_{\mathrm{C} 3}$ temperature at a reheating rate of $0.13^{\circ} \mathrm{C} / \mathrm{s}$ was observed, and it was then judged whether abnormal $\alpha$ to $\gamma$ transformation appeared. Figure 12 shows the effects of volume fraction of retained $\gamma$ and carbon content on $\alpha$ to $\gamma$ transformation behavior. The relationship among $\alpha$ to $\gamma$ transformation behavior, volume fraction of retained $\gamma$ and carbon content was investigated because it is difficult to measure the volume fraction of cementite and this fraction correlates with carbon content although the effects of volume fraction of cementite and retained $\gamma$ on $\alpha$ to $\gamma$ transformation behavior need to be investigated. Abnormal $\alpha$ to $\gamma$ transformation did not appear in the steels with a carbon content exceeding $0.1 \%$. However, abnormal $\alpha$ to $\gamma$ transformation was observed when retained $\gamma$ with a volume fraction of more than $0.5 \%$ still remained in the steels with a carbon content of $0.1 \%$ or less. It was confirmed that the carbon content and volume fraction of retained $\gamma$ remarkably affect abnormal $\alpha$ to $\gamma$ transformation.

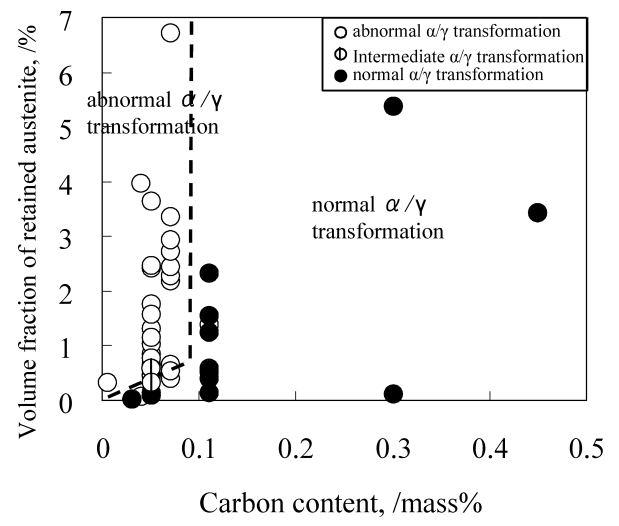

Fig. 12. Effects of carbon content and retained $\gamma$ on $\alpha$ to $\gamma$ transformation behavior.

\section{Discussion}

\section{- Mechanism of the Appearance of Abnormal $\alpha$ to $\gamma$ Transformation}

As mentioned above, three mechanisms are proposed to clarify the appearance of abnormal $\alpha$ to $\gamma$ transformation. (i) Martensite reverse transformation, (ii) the restriction of crystal orientation caused by the orientation relationship among cementite, ferrite and austenite, and (iii) the coalescence of retained $\gamma$. Here, whether the three proposed mechanisms are valid and whether consideration of an alternative mechanism is required is considered. First, the results obtained in this study are summarized as follows.

(1) Globular $\gamma$ grains of a few $\mu \mathrm{m}$ in size nucleated along the prior $\gamma$ grain boundary and acicular $\gamma$ grains along the lath boundary were observed in the $(\alpha+\gamma)$ dualphase region in the NB and NM steels with remarkable abnormal $\alpha$ to $\gamma$ transformation. Coarse $\gamma$ grains were formed by the growth and coalescence of acicular $\gamma$ grains attributed to the growth of the retained $\gamma$.

(2) Abnormal $\alpha$ to $\gamma$ transformation was remarkably suppressed due to the tempering treatment, subzero treatment, and the combined subzero treatment and tempering for NB steel because the volume fraction of retained $\gamma$ decreased and the volume fraction of cementite increased due to these treatments. However, abnormal $\alpha$ to $\gamma$ transformation occurred irrespective of tempering treatment and/or subzero treatment for NM steel. The volume fraction of retained $\gamma$ with more than $2 \%$ still remained although retained $\gamma$ reduced from 7 to $2 \%$ due to subzero treatment and/or tempering for NM steel.

(3) Normal $\alpha$ to $\gamma$ transformation occurred in the steels having a carbon content of $0.1 \%$ or higher. No abnormal $\alpha$ to $\gamma$ transformation occurred in $0.3 \%$ carbon-containing steels irrespective of $5 \%$ or higher volume fraction of retained $\gamma$. Conversely, abnormal $\alpha$ to $\gamma$ transformation occurred when a volume fraction of retained $\gamma$ of $0.5 \%$ or higher existed in the steel with a carbon content of less than $0.1 \%$.

The validity of the three hypotheses proposed as the mechanism of the appearance of abnormal $\alpha$ to $\gamma$ transformation was examined. From the result that $\alpha$ to $\gamma$ transformation behavior is dependent on the amount of retained $\gamma$ and carbon content, the assumption that the restriction of 
crystal orientation caused by the orientation relationship among cementite, ferrite and austenite did not support our results. That is, the occurrence of abnormal $\alpha$ to $\gamma$ transformation ought not to depend on the volume fraction of retained $\gamma$ and cementite if abnormal $\alpha$ to $\gamma$ transformation is governed by the restriction of the orientation relationship among ferrite, austenite, and cementite. It is doubtful that the orientation relationship between ferrite and cementite is always followed by the Bagaryatskii relationship. Matsuda et $a l^{7,8)}$ reported that acicular $\gamma$ grains were formed by martensitic reverse transformation. However, this assumption was not consistent with our results because abnormal $\alpha$ to $\gamma$ transformation is largely dependent on the volume fraction of retained $\gamma$ and cementite. If the proposal of Matsuda et al. is correct, it is thought that abnormal $\alpha$ to $\gamma$ transformation is independent of the volume fraction of retained $\gamma$ and cementite. Moreover, Matsuda et al. did not explain in detail the reason why acicular $\gamma$ grains formed by the martensitic transformation have the same crystal orientation. Our results lead to the hypothesis that the coalescence of retained $\gamma$ remained before reheating. That is, these results support Kimmins's proposal. In fact, retained $\gamma$ was observed in NB and NM steels before reheating. Abnormal $\alpha$ to $\gamma$ transformation was suppressed by decreasing the volume fraction of retained $\gamma$ before reheating. Experimental results contradicting the assumption that the coalescence of retained $\gamma$ is the mechanism of abnormal $\alpha$ to $\gamma$ transformation were not obtained in this study.

Based on these results, a schematic diagram for the mechanism of the appearance of abnormal $\alpha$ to $\gamma$ transformation is shown in Figs. 13 and 14. Acicular $\gamma$ grains that retained $\gamma$ readily coalesced because of the retained $\gamma$ with the same orientation in a coarse grain as indicated in Fig. 4. As a result, coarse grains were formed at a slow reheating rate for the bainite and martensite steels. Therefore, acicular $\gamma$ grains owing to the growth of retained $\gamma$ lead to the reconstruction of the original prior $\gamma$ grains due to the growth and coalescence of acicular $\gamma$ grains with the same orientation as that indicated in Fig. 13. On the other hand, acicular $\gamma$ grains cannot readily coalesce because of the many newly nucleated globular $\gamma$ grains by the dissolution of cementite, which has a different orientation respectively as shown in Fig. 14. This corresponds to the results of NB tempered steel, NB tempered steel after subzero treatment and BE
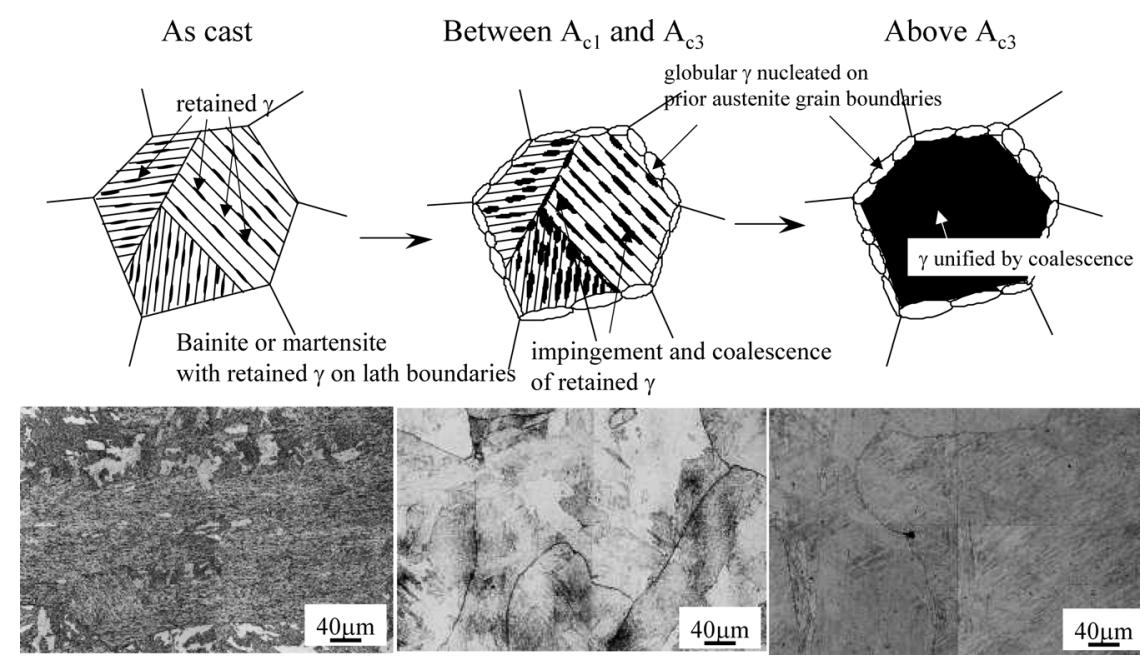

Fig. 13. Schematic drawing and optical micrographs showing abnormal $\alpha$ to $\gamma$ transformation.
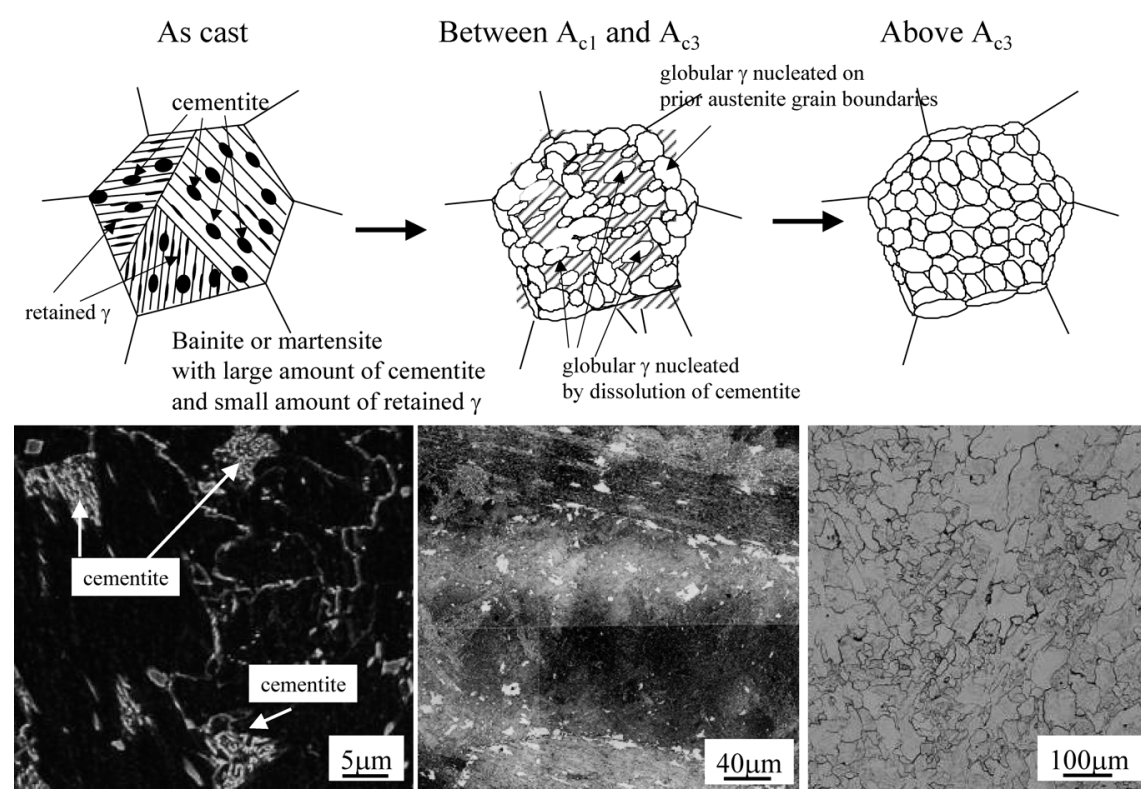

Fig. 14. Schematic drawing and micrographs showing normal $\alpha$ to $\gamma$ transformation. 
steel where abnormal $\alpha$ to $\gamma$ transformation was suppressed.

As mentioned above, coarse grains were formed by the growth and coalescence of retained $\gamma$. In contrast, the appearance of coarse grains was suppressed by increasing the volume fraction of cementite. Therefore, abnormal $\alpha$ to $\gamma$ transformation occurred when the growth and coalescence of retained $\gamma$ was more dominant than the nucleation and growth of globular $\gamma$ due to the dissolution of cementite. In other words, $\alpha$ to $\gamma$ transformation was determined by the competition between the growth and coalescence of retained $\gamma$ and the nucleation and growth of $\gamma$ nucleated due to the dissolution of cementite.

These phenomena where retained $\gamma$ along the lath boundaries grew and coalesced, remarkably differed from the diffusionless transformation or the shear mechanism. As mentioned above, the growth, impingement, and coalescence of retained $\gamma$ were observed in the $(\alpha+\gamma)$ dual-phase region for NB and NM steels. This result supports the hypothesis that retained $\gamma$ grew due to diffusion-controlled growth.

Globular $\gamma$ grains were formed along the prior $\gamma$ grain boundaries because there were no retained $\gamma$ in prior $\gamma$ grain boundaries. Globular $\gamma$ grains were nucleated and grew along the prior $\gamma$ grain boundaries due to the dissolution of cementite near prior $\gamma$ grain boundaries.

Finally, cementite may be formed during reheating due to the decomposition of retained $\gamma$ at a slow reheating rate of $0.13^{\circ} \mathrm{C} / \mathrm{s}$. $\alpha$ to $\gamma$ transformation is suppressed if a lot of cementite is formed during reheating. However, $\alpha$ to $\gamma$ transformation occurred for NB and NM steels at slow reheating rate irrespective of the fact that these steels have retained $\gamma$ of $2 \%$ or higher before reheating. Therefore, it is thought that many alloy carbides are formed rather than cementite during reheating because there are many alloying elements of carbide former such as molybdenum, titanium, chromium. This subject will be investigated in future work.

\section{Conclusions}

$\alpha$ to $\gamma$ transformation behavior was investigated in order to clarify the mechanism of the appearance of abnormal $\alpha$ to $\gamma$ transformation in which coarse $\gamma$ grains with the same grain size as those before reheating were formed when steels with a bainite or martensite structure were austenitized. The main conclusions are as follows.

(1) Fine globular $\gamma$ grains that have nucleated along the grain boundaries and coarse $\gamma$ grains are formed when steels with bainite or martensite microstructures are reheated above the $\mathrm{A}_{\mathrm{C} 3}$ temperature. The size distribution of coarse $\gamma$ grains is the same level as that prior to reheating.

(2) Many fine globular $\gamma$ grains that have nucleated along the prior $\gamma$ grain boundary are formed in the specimens quenched from the dual-phase region. Contrastingly, coarse $\gamma$ grains are formed by the growth, impingement, and coalescence of retained $\gamma$ along the lath boundary.

(3) Abnormal $\alpha$ to $\gamma$ transformation is suppressed by decreasing the volume fraction of retained $\gamma$ and by increasing the volume fraction of cementite before reheating.

These results indicate that abnormal $\alpha$ to $\gamma$ transformation occurs when the growth, the impingement and the coalescence of retained $\gamma$ along the lath boundary were more dominant than the nucleation and the growth of newly $\gamma$ nucleated by the dissolution of cementite during reheating.

\section{Acknowledgement}

We are grateful to Emeritus Professor Maki for his valuable advice and contributions to this paper.

\section{REFERENCES}

1) A. E. Neherenberg: Trans. AIME, 194 (1952), 181.

2) V. D. Sadovskii: Problems of Physical Metallurgy and Heat Treatment, Mashgiz, Moscow, (1956), 31.

3) V. D. Sadovskii and B. K. Sokolov: Problems of Physical Metallurgy and Heat Treatment, Mashgiz, Moscow, (1960), 5.

4) D. Webster and G. B. Allen: J. Iron Steel Inst., 200 (1962), 520.

5) E. Kula and M. Cohen: Trans. Am. Soc. Met., 46 (1954), 727.

6) S. S. D'Yachenko and G. V. Federov: Fiz. Met. Metalloved, 18 (1964), 73.

7) S. Matsuda and Y. Okamura: Trans. Iron Steel Inst. Jpn., 14 (1974), 363.

8) S. Matsuda and Y. Okamura: Trans. Iron Steel Inst. Jpn., 14 (1974), 444.

9) S. Watanabe and T. Kunitake: Tetsu-to-Hagané, 61, (1975), No. 1, 96.

10) R. Homma: Trans. Iron Steel Inst. Jpn., 14 (1974), 434.

11) M. R. Plichata and H. I. Aaronson: Metall. Trans., 5 (1974), 2611.

12) S. T. Kimmins and D. J. Gpooch: Met. Sci., 17 (1983), 519. 